\title{
COMMISSION 22 (METEORS)
}

\author{
President: Dr Félix de Roy. \\ Secretary: Mme G. Camille Flammarion.
}

After opening the meeting, the President paid a tribute to the memory of A. King, of England, an original member of the Commission, who died since the last General Assembly, and did excellent work in the field of meteoric astronomy, both observing assiduously and computing in connection with the Meteor Section of the B.A.A.

The President moved, and Prof. Opik seconded, the adoption of the Report, which was carried with some minor additions, with the exception of the suggestions at the end of the document. The latter were then discussed in full detail.

I. Suggestions (I3) and (I8) were referred to the General Assembly, in the form of resolutions of the Commission.

2. Dr Guth presented to the Commission a sample chart of the Gnomonic Star Atlas prepared by the Meteor Section of the Czechoslovak Astronomical Association for the use of meteor observers. This atlas will consist of $\mathrm{r} 4$ charts, as follows: (a) a North Polar Region, with centre at $\delta=+90^{\circ}$; (b) a South Polar Region, with centre at $\delta=-90^{\circ} ;(c)$ six charts with centres at $\delta=+30^{\circ}$ and $\alpha=30^{\circ}, 90^{\circ}, 150^{\circ}$, $210^{\circ}, 270^{\circ}$ and $330^{\circ} ;(d)$ six charts with centres at $\delta=-30^{\circ}$, and $\alpha=0^{\circ}, 60^{\circ}, \mathrm{I} 20^{\circ}$, $180^{\circ}, 240^{\circ}$ and $300^{\circ}$. The size of the charts will be $50 \times 50 \mathrm{~cm}$., and the radius of the projected sphere, $20 \mathrm{~cm}$. They will contain the 7796 stars of Ambronn's Sternverzeichniss down to $6 \mathrm{~m} \cdot 5$, referred to the equinox of $1950 \cdot 0$. The Atlas will also contain graticules (i) for $\delta= \pm 30^{\circ}$, for reading co-ordinates, and (ii) for $\delta=0^{\circ}$, for measuring distances and angles.

The Commission congratulated the Czechoslovak Astronomical Association upon the completion of this useful star atlas, and recommended that it be published as soon as possible, at the lowest possible sales price.

In connection with the matter of charts, Prof. Chrétien proposed that an inquiry be opened on the advantages and drawbacks of the various systems of charts to be used, either for meteor observing, or for determining radiants. He contended that it is probable that to each way of registering tracks corresponds a system of projection which is the best possible. Since he (Prof. Chrétien) was responsible for the adoption of the stereographic projection used by Rudaux and Touchet in preparing the meteor chart (centre at $\delta=+90^{\circ}$ ) of the Commission des étoiles filantes de la Société astronomique de France, he briefly indicated the reasons which made him decide to use this system.

3. Prof. Carl Störmer drew attention to the graphical method used by him for determining the situation of an auroral ray in the atmosphere, a method described in the Geofysiske Publikationer (Oslo), which might be employed also in meteor work, since it shortens computation and has already proved its practical value.

4. Prof. Störmer also said that in the case of the aurora borealis, there are essential differences, both in situation and spectrum, between aurorae occurring in the sunlit atmosphere, and aurorae occurring in the dark atmosphere. He suggested that it would be interesting to examine whether similar differences also occur in the case of meteors.

5. With regard to suggestion (9), Prof. Leonard communicated that Dr A. L. Coulson, of the Geological Survey of India, is at present engaged, at the British Museum of Natural History in London, England, in compiling a complete up-to-date catalogue of meteoritic falls and finds, somewhat along the lines of Prior's Catalogue

A U VI 
of Meteorites and its Appendix (1927). The Commission welcomed this important announcement, and expressed the hope that Dr Coulson's work might soon be published.

6. With regard to suggestion (Io) of the Report, it was resolved, after discussion, that the President of the Commission should approach the Editor of the Astronomischer Jahresbericht, in order to obtain, if possible, that the excellent bibliography of meteorites contained in this publication should be further extended by the inclusion of more references from geophysical, geological and petrographical publications, on the lines of the lists of papers relating to meteorites published for some time by the Society for Research on Meteorites. The authors of these lists would be ready to offer their help in this matter.

7. With regard to suggestion (II), Prof. Leonard suggested, and the Commission approved, that, pending some international agreement on terminology and notations in this field, scientific writers be asked to make a consistent and unequivocal distinction in the use of the terms meteor and meteorite, the former referring only to the luminous phenomenon, the second to the body itself; either mass or particle.

8. In connection with Dr Whipple's paper on the results of photographic work at Harvard, the Commission, on Miss Hoffleit's suggestion, recommended that meteor observers, in addition to the phenomena they generally register, should also note, whenever possible, the point along the path at which a meteor attains maximum brightness. This point may be marked by a small cross line.

9. In photographic observations, Dr Vandekerkhove suggested the use, instead of or alternatively to the rotating sector, of a grating of heavy wires placed in front of the plate. He said that, if two such gratings were used with a fixed camera directed towards the zenith, one made of parallel wires, the other of a different pattern and of known relative orientation, both being given a uniform motion, then, not only the path, the velocity and the deceleration of a meteor, but also the direction of its flight might be automatically registered.

Io. In a written communication, Prof. Bosler suggested that the problem of defining by suitable experiments the true apparent magnitude of a meteor be given further attention. The Commission endorsed the importance of such a study.

II. The following communications were made to the Commission on the occasion of its two meetings:

(I) Les expériences sur un météore artificiel, par J. Svoboda.

(2) Distribution of Small Particles about the Sun and the Origin of the Zodiacal Light, by Fletcher G. Watson, Jr. (read by Miss D. Hoffleit).

(3) On the Technique of the Determination of Meteor Velocities by the Rocking Mirror Method, by E. Opik.

(4) Preliminary Report on a Swarm of Fireballs seen in Southern Sweden on May 27, I938, by Axel Corlin.

(5) Meteororganisation in Wien und Diagramme zur Meteorwissenschaft, von O. Thomas.

\section{Sub-commission on Zodiacal Light and Kindred Phenomena}

President: Prof. Issei Yamamoto.

The President's Draft Report (p. I72), of which typewritten copies had been distributed, was taken up, partly discussed, and adopted after some alterations.

Prof. M. N. Donitch raised the question of the origin of the zodiacal light and communicated the results of the observations he obtained during the winters of 